\title{
geografiar
}

\section{Komuniti pembelajaran profesional sebagai budaya kolaborasi profesional sekolah: Teori dan amalan}

\author{
Kamarudin Ismail ${ }^{1}$, Rosnah Ishak ${ }^{1}$, Fanny Kho Chee Yuet $^{1}$, Siti Hajar Kamaruddin ${ }^{2}$ \\ ${ }^{1}$ Fakulti Pengurusan dan Ekonomi, Universiti Pendidikan Sultan Idris \\ ${ }^{2}$ Fakulti Perniagaan, Ekonomi dan Pembangunan Sosial, Universiti Malaysia Terengganu \\ Correspondence: Kamarudin Ismail (email: kamalcikdeen@gmail.com)
}

Received: 15 November 2019; Accepted: 22 November 2019; Published: 25 November 2019

\begin{abstract}
Abstrak
Budaya pengasingan guru telah menjadi tradisi dalam sistem pendidikan di kebanyakan negara. Walau bagaimanapun, budaya ini dikatakan tidak berupaya meningkatkan pencapaian murid khususnya dalam arus sistem pendidikan yang semakin kompleks. Kini, reformasi terhadap sistem pendidikan melalui kolaborasi menjadi satu keperluan bagi menghadapi persaingan pendidikan di peringkat global. Namun, beberapa kajian mendapati budaya kolaborasi profesional agak sukar dibentuk dalam komuniti pembelajaran profesional. Justeru, kajian ini bertujuan untuk menganalisis dan membincangkan kajian terkini tentang budaya kolaborasi melalui komuniti pembelajaran profesional. Kajian ini adalah berbentuk sintesis penyelidikan secara kualitatif. Kerangka teori yang dirujuk dalam kajian ini adalah berdasarkan Teori Aktiviti Budaya dan Sejarah (Cultural Historical Activity Theory). Fokus kajian adalah ke atas kolaborasi guru sekolah dan sumber data diperoleh daripada artikel dan buku yang diterbitkan. Hasil kajian ini telah menemukan enam tema utama. Tema tersebut ialah kepentingan budaya kolaborasi, bentuk budaya kolaborasi, kebaikan dan keburukan kolaborasi, amalan budaya kolaborasi, halangan budaya kolaborasi dan strategi untuk meningkatkan budaya kolaborasi. Amalan di dalam komuniti pembelajaran profesional didapati mampu membentuk budaya kolaborasi profesional di sekolah.
\end{abstract}

Katakunci: budaya kolaborasi, kolaborasi guru, komuniti pembelajaran profesional, pembangunan profesionalisme, sekolah 


\title{
Professional learning communities as a professional collaboration culture in school: Theory and practice
}

\begin{abstract}
The culture of teacher isolation has been a tradition in most of the countries' education system. However, this culture is not capable of improving student achievement particularly in the complexity of the current education system. Education system reform through collaboration indeed a need to face global education competition nowadays. Yet, some studies found that professional collaborative culture is difficult to form through professional learning communities. Thus, the aim of the study is to analyze and discuss the latest research findings on the collaborative culture through professional learning communities. This study applies the qualitative research synthesis. The theoretical framework is based on Cultural Historical Activity Theory. The focus of this study is on teacher collaboration and sources of the data are from articles and books publication. This study finds six themes. They are the importance of collaborative culture, forms of collaborative culture, the advantages and disadvantages of collaboration, collaborative culture practices, barriers to collaborative culture and strategies to promote collaboration culture. The practice of professional learning communities also shows that it is able to form a professional collaborative culture in school.
\end{abstract}

Keywords: collaborative culture, teacher collaboration, professional learning communities, professional development, school

\section{Pengenalan}

Arus persaingan global pendidikan menjadikan kebanyakan negara melakukan reformasi dalam sistem pendidikan. Gerakan reformasi pendidikan ini lebih menumpu kepada proses pembangunan profesionalisme guru khususnya pembentukan budaya kolaborasi (Carpenter, 2018). Budaya kolaborasi merupakan salah satu elemen penting dalam memastikan kelestarian penambahbaikan sekolah (Lee \& Louis, 2019). Budaya kolaborasi profesional ini diamalkan dalam komuniti pembelajaran profesional. Komuniti pembelajaran profesional telah dilaksanakan oleh negara yang telah menunjukkan prestasi yang tinggi dalam penilaian peperiksaan antarabangsa seperti negara Finland, Singapura dan Kanada. Salah satu kunci kejayaan mereka adalah melalui budaya kolaborasi profesional tersebut (Hargreaves \& O' Connor, 2017).

Komuniti pembelajaran profesional dibentuk apabila guru bekerjasama dalam budaya kolaborasi untuk menganalisis pencapaian murid, berkongsi pedagogi, dan memperbaiki pengajaran, pembelajaran dan pencapaian murid (DuFour, 2004). Komuniti pembelajaran profesional sebagai suatu struktur yang memberi peluang kepada guru dan pemimpin sekolah berkolaborasi (Hairon \& Tan, 2016). Justeru, komuniti pembelajaran profesional merupakan rangkaian formal yang menjadi landasan kepada usaha reformasi untuk meningkatkan kolaborasi guru dan sebagai amalan penambahbaikan sekolah (Carpenter, 2018).

Namun, bagi menjadikan komuniti pembelajaran profesional sebagai budaya kolaborasi profesional yang berterusan bukanlah sesuatu yang mudah (Zhang, Yuan \& Yu, 2017). Hal ini kerana guru-guru masih cenderung dalam budaya pengasingan diri kerana kurangnya kefahaman 
dan kemahiran dalam berkolaborasi (Siti Nafsiah, Zuraidah, Abdul Jalil \& Salwati, 2018). Sesuatu perubahan terhadap tingkah laku khususnya yang melibatkan amalan seharian guru memerlukan masa untuk dilaksanakan. Pelbagai aspek perlu diambil kira sebelum sesebuah komuniti pembelajaran profesional menjadi budaya kolaborasi profesional.

Justeru, persoalan utama dalam kajian ini ialah: "Bagaimanakah budaya kolaborasi profesional dapat dibentuk melalui komuniti pembelajaran profesional di sekolah ?" Berdasarkan persoalan tersebut, kajian ini bertujuan menganalisis dan membincangkan literatur terkini tentang komuniti pembelajaran profesional dan perkaitannya dengan budaya kolaborasi guru di sekolah. Bahagian seterusnya dalam kajian ini menghuraikan kerangka teori kajian yang merujuk kepada Teori Aktiviti Budaya dan Sejarah (CHAT), metodologi kajian, evolusi kolaborasi profesional, kepentingan kolaborasi, kebaikan dan keburukan kolaborasi, halangan kepada kolaborasi, strategi bagi meningkatkan budaya kolaborasi profesional dan akhir sekali kesimpulan kajian.

\section{Kajian literatur}

\section{Kerangka teori kajian}

Kajian ini mengaitkan Teori Aktiviti Budaya dan Sejarah (CHAT) sebagai model sokongan kajian. Teori ini menekankan persekitaran sosial sebagai asas perkembangan dan pembelajaran manusia yang dikembangkan oleh Leontiev (1981) berdasarkan teori yang diasaskan Vygotsky. Teori ini dapat menilai hubungan antara manusia, artifak perantara dan matlamat yang dipengaruhi dan dibentuk oleh struktur sosial, budaya dan sejarah dalam sesebuah konteks komuniti (Trust, 2017).

Menurut Vygotsky (1978), pembelajaran individu perlu disokong oleh orang lain yang lebih berpengetahuan dan berkemahiran seperti yang dinyatakan dalam zone of proximal development. Seterusnya teori ini dikembangkan dengan melibatkan sistem aktiviti (activity system) dalam teori CHAT. Sistem aktiviti ialah tindakan kolektif individu yang dibina oleh rangkaian elemen sosiobudaya dan sejarah bagi mencapai matlamat tertentu. Oleh itu, komuniti pembelajaran profesional dianggap sebagai sebuah sistem aktiviti yang disokong oleh rangkaian elemen. Rangkaian elemen tersebut termasuklah objek, hasilan, subjek, artifak perantara, peraturan, pemeringkatan peranan (division of labour) dan komuniti dihuraikan seperti yang berikut:

a) Objek dan hasilan - Objek ialah matlamat daripada sesuatu aktiviti yang dilakukan. Contohnya, matlamat seseorang guru menyertai pasukan komuniti pembelajaran profesional ialah untuk meningkatkan pengetahuan pedagogi. Manakala hasilan merujuk kepada kesan tindakan yang dilakukan oleh individu.

b) Subjek - Subjek merujuk kepada penglibatan individu dalam aktiviti. Matlamat yang ingin dicapai oleh subjek dapat membentuk identiti dan pengetahuan melalui interaksi dengan elemen lain dalam sistem aktiviti.

c) Artifak perantara - Subjek menggunakan artifak perantara untuk mencapai matlamat yang hendak dicapai. Artifak perantara boleh terdiri daripada unsur bahan atau unsur konseptual. Unsur konseptual ialah seperti model mental, simbol, motivasi, bahasa dan bentuk budaya yang lain, manakala unsur bahan ialah seperti teknologi baru, komputer, pakar luar. 
d) Komuniti, pemeringkatan peranan dan peraturan - Komuniti merujuk kepada kumpulan individu yang mempunyai minat yang sama. Komuniti juga dihubungkan dengan budaya dalam sistem aktiviti. Seseorang individu mempunyai peranan yang berbeza dalam sesebuah komuniti disebabkan oleh perbezaan tahap kemahiran, pengetahuan dan minat. Setiap komuniti mempunyai peraturan tertentu yang disepakati bersama sebagai panduan kepada tindakan, tingkah laku dan interaksi individu dalam komuniti tersebut.

\section{Kaedah kajian}

Kajian ini ialah sebuah kajian sintesis (research synthesis) berdasarkan analisis artikel dan buku yang diterbitkan. Kaedah kajian secara sintesis telah terbukti kesahannya dan semakin mendapat perhatian para pengkaji dalam membentuk pengetahuan baru pada masa kini (Suri, 2014). Kajian sintesis ialah terma utama (umbrella term) yang menggunakan pelbagai bukti, perspektif kaedah dan teknik yang dilakukan oleh pengkaji bagi melaporkan hasil sintesis kajian sama ada secara kuantitatif, kualitatif atau gabungan kedua-duanya (Cohen, Manion \& Morrison, 2018). Oleh itu, pengkaji telah menggunakan kaedah sintesis secara kualitatif bagi mengetahui bagaimana komuniti pembelajaran profesional dapat membentuk budaya kolaborasi profesional di sekolah.

Justeru, kajian sintesis ini melibatkan beberapa langkah sistematik seperti yang disarankan oleh Gough (2007):

1) Mengenal pasti persoalan kajian

2) Menentukan skop dan sumber kajian - skop kajian melibatkan komuniti pembelajaran profesional dan perkaitannya dengan budaya kolaborasi di sekolah. Sumber kajian melibatkan artikel berbentuk akademik jurnal berwasit dan buku berkaitan dengan skop kajian.

3) Strategi pencarian kajian - pencarian data kajian menggunakan pangkalan data Taylors and Francis, Web Of Science, Scopus, Google Scholar dan Myjurnal dengan menggunakan kata kunci collaborative culture, professional learning communities, budaya kolaborasi dan komuniti pembelajaran profesional.

4) Penilaian kajian - Pemilihan bahan kajian berdasarkan kriteria yang ditetapkan. Pengkaji telah memilih 26 artikel dan 6 buah buku untuk dianalisis.

5) Analisis dan sintesis kajian dikaitkan dengan teori CHAT seperti yang dihuraikan dalam kerangka teori kajian.

6) Laporan dapatan kajian

\section{Hasil kajian dan perbincangan}

Hasil dapatan kajian dihuraikan mengikut tema yang berikut iaitu kepentingan budaya kolaborasi, bentuk budaya kolaborasi, kebaikan dan keburukan kolaborasi, amalan budaya kolaborasi, halangan budaya kolaborasi dan strategi untuk meningkatkan budaya kolaborasi profesional. Terlebih dahulu dihuraikan secara ringkas evolusi budaya kolaborasi profesional bagi memahami sejarah kolaborasi guru. 


\section{Evolusi budaya kolaborasi profesional}

Terdapat lima fasa evolusi kolaborasi profesional seperti yang dinyatakan oleh Hargreaves dan O'Connor (2017). Secara ringkasnya, fasa pertama melibatkan budaya mengajar. Pada fasa ini, guru menekankan kepada pengajaran sendiri yang menjadi tradisi profesion perguruan. Pada tahun 1930-an, sekumpulan ahli sosiologi telah mendapati bahawa identiti dan tindakan seseorang dipengaruhi oleh orang di sekeliling. Oleh itu, hubungan dengan rakan adalah penting dalam budaya ini. Guru hanya menumpukan kepada pengajaran sahaja. Masa yang terluang digunakan untuk bersosial dengan rakan guru yang lain.

Fasa kedua pula, budaya individualisme. Secara umumnya, budaya ini dikaitkan dengan sikap guru yang lebih suka melakukan kerja secara sendirian. Mereka bersikap konservatif terhadap sesuatu perubahan. Kajian Lortie (1975) telah menemui guru yang bekerja sendirian menjadi penghalang kepada kreativiti dan arahan pengajaran.

Fasa ketiga, budaya individualisme dan kolaborasi. Terdapat perbandingan kedua-dua budaya dalam fasa ini. Kajian Rosenholtz (1989) menemui guru bekerja secara berpasukan dapat meningkatkan pembelajaran murid. Kajian ini menunjukkan bahawa keberkesanan budaya kolaborasi dalam meningkatkan pencapaian murid.

Fasa keempat, kolaborasi lemah dan kuat. Secara umumnya, fasa ini menunjukkan perbezaan jenis-jenis kolaborasi dari yang kuat hingga yang lemah, khususnya dalam menambah baik sekolah. Kajian Little (1990), menemui kontinum kejeleketan dalam sesuatu kolaborasi. Kolaborasi dikatakan lemah jika kejeleketan berasaskan gosip, dialog dan perkongsian idea antara guru sahaja tanpa adanya sesuatu tindakan. Kolaborasi yang kuat pula apabila kejeleketan terhasil dengan kerja yang dilakukan bersama. Mereka memikul tanggungjawab secara kolektif terhadap pembelajaran murid.

Fasa kelima, mereka bentuk inisiatif dan intervensi kolaborasi profesional. Fasa yang melibatkan inisiatif dan reformasi melalui reka bentuk kolaborasi sebagai strategi penambahbaikan keseluruhan sistem seperti yang diamalkan di kebanyakan negara pada masa kini seperti komuniti pembelajaran profesional dan pasukan data.

Fasa keenam, tentangan terhadap kolaborasi. Fasa terkini yang mempersoalkan keberkesanan kolaborasi. Beberapa pandangan sarjana yang menyatakan kolaborasi profesional tidak memberi apa-apa kesan atau sebahagian kecil sahaja berkesan terhadap pencapaian hasil murid.

\section{Kepentingan budaya kolaborasi}

Guru menjadi wahana untuk meningkatkan pengetahuan dan kemahiran pekerja pada masa hadapan (Hairon \& Tan, 2016). Selaras dengan arus kurikulum pendidikan yang kompleks dan bersifat global, murid perlu mempunyai kemahiran-kemahiran tertentu sebelum mereka memasuki alam pekerjaan. Grey (2016), dipetik dalam Fullan, Quinn dan McEachen (2017), telah menyenaraikan sepuluh kemahiran yang perlu ada bagi pekerja pada masa hadapan seperti yang ditunjukkan dalam Jadual 1.

Berdasarkan Jadual 1, beberapa kemahiran turut dikaitkan dengan kolaborasi seperti kolaborasi virtual, koordinasi dengan orang lain, perundingan dan pengurusan manusia. Oleh itu, persekitaran kolaborasi perlu ditonjolkan di sekolah dan guru sebagai model sebenar kepada murid untuk belajar kemahiran kolaborasi tersebut (Vangrieken, Dochy, Raes \& Kyndt, 2015). Selain itu, kolaborasi merupakan instrumen yang sangat berkesan dalam pembangunan profesional berterusan, meningkatkan pembelajaran murid, memberi peluang kepada guru untuk 
memperbaiki amalan dan kemahiran pengajaran, serta sebagai medium kepada penambahbaikan sekolah (Bantwini, 2018). Tuntasnya, kolaborasi ialah perkongsian nilai dan kepakaran bagi meningkatkan pengajaran guru dan pencapaian murid. Kolaborasi dikatakan sebagai salah satu elemen sistem penambahbaikan sekolah secara kendiri yang berjaya diamalkan oleh beberapa negara seperti United Kingdom dan Kanada (Hadfield \& Ainscow, 2018).

Jadual 1. Kemahiran pekerja pada masa hadapan

\begin{tabular}{|c|c|c|}
\hline Apollo Institute 2020 & World Economic Forum 2015 & World Economic Forum 2020 \\
\hline 1. Membuat pertimbangan & $\begin{array}{l}\text { 1. Menyelesaikan masalah yang } \\
\text { kompleks }\end{array}$ & $\begin{array}{l}\text { 1. Menyelesaikan masalah yang } \\
\text { kompleks }\end{array}$ \\
\hline 2.Kebijaksanaan sosial & 2. Koordinasi dengan orang lain & 2. Pemikiran kritikal \\
\hline 3. Pemikiran adaptif & 3. Pengurusan manusia & 3. Kreativiti \\
\hline 4. Kompetensi merentas budaya & 4. Pemikiran kritikal & 4. Pengurusan manusia \\
\hline 5.Pemikiran komputasi & 5. Perundingan & 5. Koordinasi dengan orang lain \\
\hline 6.Literasi media baru & 6. Kawalan kualiti & 6. Kebijaksanaan emosi \\
\hline 7.Transbidang & 7. Orientasi perkhidmatan & $\begin{array}{l}\text { 7. Pembuatan keputusan dan } \\
\text { pengadilan }\end{array}$ \\
\hline 8.Reka bentuk pemikiran & $\begin{array}{l}\text { 8. Pembuatan keputusan dan } \\
\text { pengadilan }\end{array}$ & 8. Orientasi perkhidmatan \\
\hline 9. Pengurusan Kognitif & 9. Pendengar aktif & 9. Perundingan \\
\hline 10.Kolaborasi virtual & 10. Kreativiti & 10. Fleksibel kognitif \\
\hline
\end{tabular}

Sumber: Fullan, Quinn \& McEachen, 2017

\section{Bentuk budaya kolaborasi}

Budaya kolaborasi berlaku dalam aktiviti seharian, program dan acara sekolah, semasa sesi pertukaran idea dan pengalaman, serta analisis amalan pengajaran (Shakenova, 2017). Budaya kolaborasi terbentuk apabila pendidik secara intelektual dan fizikal berkongsi kualiti pengajaran dan pembelajaran dalam pertemuan secara bersemuka. Mereka bersama menetapkan hala tuju bagi mencapai visi pengajaran dan pembelajaran. Setiap ahli dalam pasukan kolaborasi mempunyai nilai dan pandangan yang saksama (Carpenter, 2017).

Berdasarkan pandangan Hargreaves (1994), terdapat lima bentuk budaya kolaborasi yang mempunyai ciri-ciri yang berbeza antara satu sama lain. Antaranya ialah: 1) pengasingan, 2) kolaborasi, 3) kejeleketan yang dipaksa, 4) "balkanization", 5) "moving mosaic" yang diterangkan seperti berikut:

1) Pengasingan - bentuk budaya ini mendapat kritikan oleh sesetengah sarjana misalnya Banerjee, Stearns, Moller dan Mickelson (2017) berpendapat guru bekerja secara sendirian tidak berupaya meningkatkan kemahiran diri disebabkan oleh kurangnya kepuasan bekerja. Namun, sesetengah kes, mereka mungkin lebih komited dalam meningkatkan prestasi murid (Lee \& Lee, 2018).

2) Kolaborasi - antara ciri-cirinya termasuklah dibentuk sendiri oleh guru sendiri. Ia disokong oleh pengurusan dan dilakukan secara sukarela tanpa memberi masalah kepada pentadbir. Kolaborasi juga berorientasikan pembangunan, berlaku pada bila-bila masa dan di mana sahaja serta mempunyai hasil kerja yang tidak terjangka.

3) Kejeleketan yang dipaksa - berbeza dengan budaya kolaborasi, kolaborasi ini dibentuk atas arahan pentadbir. Masa dan tempat kolaborasi ditetapkan oleh pentadbir dan hasil kolaborasi dapat dijangka. Budaya seperti ini boleh memberi kesan positif dan juga negatif kepada sesebuah organisasi dan ia bergantung kepada situasi yang digunakan. 
4) Budaya "balkanization" - merujuk kepada pasukan kolaborasi dalam sekolah yang bersaing antara satu sama lain. Budaya ini mewujudkan jurang sempadan antara pasukan, personal guru berdasarkan subjek atau panitia tertentu, sub-pasukan yang kekal dan perspektif politik yang merujuk kepada kawalan kuasa yang mempengaruhi pengagihan sumber dan promosi.

5) 'moving mosaic' - budaya yang dikaitkan dengan fleksibel, kreativiti, berisiko dan pembangunan profesional berterusan dalam kalangan warga sekolah. Sempadan antara jabatan agak longgar dan guru boleh berkolaborasi lebih dari satu pasukan, guru juga boleh belajar daripada rakan yang lain yang berbeza jabatan. Ketua jabatan dipilih oleh guru bagi tempoh tertentu dan hubungan antara guru menjadikan perbincangan dan penyelesaian masalah dapat dilakukan secara terbuka.

\section{Kebaikan dan keburukan kolaborasi}

Terdapat beberapa faedah kolaborasi. Bilangan ahli dalam sesuatu kolaborasi dalam komuniti pembelajaran profesional dikaitkan dengan percambahan pengetahuan (Stoll \& Louis, 2007) seperti ditunjukkan dalam Jadual 2.

Jadual 2. Keahlian komuniti pembelajaran profesional dan pengembangan pengetahuan

\begin{tabular}{|c|c|}
\hline Keahlian komuniti pembelajaran profesional & Pengetahuan \\
\hline $\begin{array}{l}\text { Komuniti pembelajaran profesional yang asal } \\
\text { (kumpulan guru) }\end{array}$ & Pedagogi dan pengetahuan lain yang berkaitan \\
\hline $\begin{array}{l}\text { Diperluaskan keahlian dalam sekolah seperti staf } \\
\text { sokongan, pentadbir, ahli lembaga sekolah dan murid }\end{array}$ & $\begin{array}{l}\text { Pengetahuan profesional lain seperti pengetahuan } \\
\text { keperluan pembelajaran, pengetahuan murid, } \\
\text { pengetahuan luar (kewangan) }\end{array}$ \\
\hline $\begin{array}{l}\text { Diperluaskan antara sekolah, rangkaian sekolah } \\
\text { (dalam daerah) }\end{array}$ & Akses kepada pengetahuan yang lebih luas \\
\hline Diperluaskan termasuk ibu bapa & $\begin{array}{l}\text { Pengetahuan konteks setempat, pengetahuan tentang } \\
\text { kanak-kanak secara individu }\end{array}$ \\
\hline Diperluaskan termasuk komuniti luar dan agensi lain & $\begin{array}{l}\text { Pengetahuan profesional misalnya } \\
\text { perniagaan }\end{array}$ \\
\hline $\begin{array}{l}\text { Diperluaskan melangkaui sempadan negara, peserta } \\
\text { daripada konteks budaya yang berbeza }\end{array}$ & Pengetahuan antara budaya \\
\hline
\end{tabular}

Berdasarkan Jadual 2, sistem sosial bagi sesebuah komuniti pembelajaran profesional bukan sahaja dilingkari dalam sekolah, antara sekolah malah merentasi sempadan negara. Pengetahuan guru secara asasnya mengandungi pengetahuan subjek, pedagogi subjek dan pengetahuan berkaitan perkembangan murid (Stoll \& Louis, 2007). Sesetengah pengetahuan profesional yang lain perlu khususnya pengetahuan yang kritikal dalam menambah baik sekolah. Justeru, kolaborasi yang mantap mempunyai proses yang sistematik yang memerlukan guru bersama ahli komuniti yang lain menambah baik sekolah melalui perkongsian kepelbagaian pengetahuan profesional dan kepakaran masing-masing (Mohd Faiz, Rozaimie \& Jamal, 2016)

Antara kebaikan kolaborasi yang lain (Bantwini, 2018) ialah: 1) kolaborasi membantu sekolah dalam membangunkan nilai kepercayaan dengan saling kebergantungan secara positif dalam kalangan guru, 2) meningkatkan efikasi kendiri, 3) mengurangkan guru yang bekerja secara menyendiri, 4) mempromosikan persekitaran secara bersemuka, 5) menyediakan sokongan sosial dalam menguruskan stress dan "burnout" dalam kalangan guru, 6) menyediakan pembelajaran 
profesional guru, 7) sebagai motivasi kepada amalan pembelajaran dan kolaborasi, dan 8) penambahbaikan hasil pembelajaran murid.

Walau bagaimanapun, kolaborasi juga bukanlah strategi yang dapat menyelesaikan semua masalah malah ia juga mendatangkan risiko kepada sesuatu sistem (Vangrieken et al., 2015). Misalnya, kolaborasi menyebabkan tekanan kerja, kehilangan autonomi, konflik intrapersonal dan percanggahan pendapat (Schaap et al., 2018). Hal ini juga disebabkan oleh sesetengah bentuk kolaborasi adalah sangat lemah dan hanya menumpukan kepada perbincangan dan pertukaran idea antara guru dan pemimpin sekolah tanpa sebenarnya bertindak dan mengambil tanggungjawab secara kolektif untuk memperbaiki pembelajaran murid terutamanya murid yang tercicir.

Selain itu, hasil kajian Hargreaves dan O'Connor (2017) terhadap The New Teacher Project di Amerika Syarikat mendapati terdapat sedikit sahaja peningkatan kualiti guru walaupun setiap guru diberikan sejumlah besar peruntukan untuk aktiviti pembangunan profesionalisme termasuklah aktiviti kolaborasi. Mereka juga mendapati, kebanyakan guru yang berkhidmat tiga atau empat tahun yang pertama tidak menunjukkan peningkatan dalam prestasi. Kebanyakan guru di Amerika Syarikat berpandangan masa yang digunakan untuk aktiviti pembangunan profesionalisme tidak memberi kesan kepada mereka.

\section{Amalan budaya kolaborasi}

Berdasarkan model-model komuniti pembelajaran profesional daripada beberapa buah negara di timur dan barat yang dianalisis oleh pengkaji, aktiviti kolaborasi merupakan antara elemen utama yang menggerakkan proses perlaksanaan komuniti pembelajaran profesional. Antaranya model komuniti pembelajaran profesional oleh Louis, Marks dan Kruse (1996), DuFour dan Eaker (1998), Thompson, Greff dan Niska (2004), Little (2006), Stoll, Bolam, Wallace dan Thomas. (2006), Reichstetter (2006), Blankstein (2004), Lomos, Hofman dan Bosker (2011), Sleegers, den Brok, Verbiest, Moolenaar dan Daly (2013), Sun-Keung Pang, Wang dan Lai-Mei Leung (2016) dan Zhang dan Sun (2018). Setiap model komuniti pembelajaran profesional tersebut mempunyai amalan kolaborasi yang berbeza-beza mengikut konteks yang dijalankan oleh pengkaji seperti konteks sekolah, lokasi dan geografi. Perbezaan sistem pendidikan, sejarah pendidikan dan budaya setempat turut menjadikan setiap amalan kolaborasi berbeza (Stoll et al., 2006)

Oleh itu, beberapa contoh amalan kolaborasi berdasarkan dua bentuk model komuniti pembelajaran profesional dari negara China dan negara Belanda dibincangkan dalam kajian ini. Misalnya, amalan kolaborasi dalam Model komuniti pembelajaran profesional Zhang dan Sun (2018) termasuklah: 1) guru menolong dan membantu antara satu sama lain di sekolah, 2) kejujuran semasa perbincangan dijalankan, 3) pandangan yang berbeza dalam perbincangan dapat ditangani dengan baik, 4) kesediaan guru untuk berkolaborasi, 5) perbincangan secara terbuka apabila membincangkan masalah yang dihadapi dalam pengajaran.

Amalan kolaboratif secara tidak formal turut diamalkan guru iaitu: 1) guru secara tidak formal saling bertukar idea dan amalan pengajaran mereka, 2) guru mempunyai hak untuk memulakan pembaharuan berdasarkan amalan pengajaran mereka, dan 3) meningkatkan pembelajaran pelajar ialah matlamat kebanyakan guru.

Seterusnya Model Sleegers et al. (2013), amalan kolaborasi dilakukan dalam dimensi pembelajaran kolektif iaitu: 1) guru bekerjasama untuk memperoleh dan mengaplikasikan pengetahuan baru, kemahiran, dan strategi, 2) hubungan yang sedia ada di kalangan guru 
menunjukkan komitmen guru terhadap penambahbaikan sekolah, 3) guru bekerjasama untuk membantu pelajar menyelesaikan masalah, dan 4) guru terlibat dalam dialog profesional di mana idea-idea berbeza dinilai antara satu sama lain.

Dalam dimensi perkongsian amalan pula, 1) guru memerhatikan pengajaran rakan lain dan memberi maklum balas tentang pengajaran mereka, 2) perkongsian idea dan cadangan secara tidak formal untuk meningkatkan prestasi pelajar murid, 3) perbincangan kerja murid untuk memperbaiki amalan bilik darjah mereka, dan 4) penglibatan dalam pelbagai bentuk interaksi rangkaian sosial sebagai menyokong pembelajaran profesional dan penambahbaikan sekolah.

\section{Halangan budaya kolaborasi}

Beberapa halangan didapati dalam melestarikan budaya kolaborasi. Terdapat pelbagai aspek halangan kepada kolaborasi profesional (Zhang et al., 2017). Antaranya masa, budaya dan mikropolitik seperti yang dikemukakan oleh Shakenova (2017).

Masa merupakan halangan yang terbesar dalam inovasi dan pengurusan perubahan. Zhang et al. (2017) telah mengenal pasti lima halangan kepada kolaborasi yang berkaitan dengan masa iaitu: proses pembentukan kolaborasi memerlukan masa yang panjang, masa perkongsian yang tidak mencukupi, guru tidak berminat memperuntukkan masa untuk berkolaborasi disebabkan oleh polisi tertentu, masa berkolaborasi agak terhad disebabkan oleh kesibukan kerja dan pengurusan masa yang kurang baik oleh pentadbir.

Mikropolitik. Menurut Blase (1991), mikropolitik merujuk kepada penggunaan kuasa yang formal dan tidak formal oleh individu dan kumpulan untuk mencapai matlamat organisasi. Wan, Law dan Chan (2017) menyatakan autonomi guru akan terjejas disebabkan oleh mikropolitik yang ada dalam sistem sekolah. Perbezaan pandangan antara pentadbir dan guru turut menjejaskan aktiviti kolaborasi khususnya dalam membuat sesuatu keputusan seperti polisi dan visi sekolah.

Manakala dari aspek budaya pula, Hargreaves dan Fullan (1992) menyatakan tiga bentuk budaya kolaborasi yang perlu dielakkan. Antaranya ialah: 1) Kejeleketan yang dipaksakolaborasi dibentuk atas arahan pihak atasan dan bukan secara sukarela yang boleh menyebabkan hilangnya motivasi untuk berkolaborasi, 2) budaya "balkanized"- budaya yang memisahkan dan berlakunya persaingan antara kumpulan yang mempunyai matlamat tersendiri. Hal ini akan menyebabkan konflik antara individu dan kumpulan serta kurangnya komunikasi dan interaksi sesama mereka, 3) budaya yang selesa-guru berkolaborasi dalam jangka masa yang pendek tanpa adanya perkongsian nilai.

\section{Strategi meningkatkan budaya kolaborasi profesional}

Terdapat pelbagai bentuk aktiviti kolaborasi profesional. Al-Jammal (2015) telah menyenaraikan model-model pembelajaran dewasa yang merupakan antara aktiviti-aktiviti bagi membudayakan kolaborasi profesional di dalam sekolah dan luar sekolah seperti ditunjukkan dalam Jadual 3.

Bagi Carpenter (2018), telah mencadangkan suatu bentuk model yang menggalakkan budaya kolaborasi dalam komuniti pembelajaran profesional profesional. Dalam model tersebut, perkongsian intelektual dan fizikal dalam suatu ruang kerja. Beliau telah menggabungkan ciriciri komuniti pembelajaran profesional, budaya sekolah dan kolaborasi bagi membentuk model tersebut. Antara ciri perkongsian intelektual dan fizikal termasuklah: 1) perkongsian akauntabiliti 
dan pembuatan keputusan, 2) inkuiri secara kolaboratif, 3) perkongsian amalan, 4) perkongsian matlamat, 5) perkongsian kepimpinan, dan 6) sumbangan secara sukarela.

Selain itu peranan kepimpinan diperlukan dalam melahirkan budaya kolaborasi profesional. Kajian Andin et al. (2019) membuktikan peranan pemimpin sebagai penggerak utama kepada transformasi persekitaran sekolah. Manakala, Fullan et al. (2017) telah merangka suatu Kerangka Keselarasan yang menghubungkan peranan pemimpin dalam membentuk pendekatan sistemik pembelajaran mendalam (deep learning) yang mengandungi empat buah komponen utama yang saling berkait iaitu fokus kepada hala tuju, percambahan budaya kolaborasi, pembelajaran mendalam dan memastikan akauntabiliti. Pemimpin berfungsi sebagai penggerak, penghubung dan mengintegrasikan keempat-empat komponen tersebut.

Jadual 3. Model pembelajaran dewasa dan huraian definisi

\begin{tabular}{|c|c|}
\hline Model & Huraian definisi \\
\hline Kumpulan pembelajaran & $\begin{array}{l}\text { Pasukan guru berbincang berkenaan suatu topik yang dipersetujui untuk } \\
\text { dibincangkan bersama. Pasukan ini memberi ruang untuk ahli kumpulan } \\
\text { berefleksi, belajar, merancang bersama-sama. }\end{array}$ \\
\hline Bimbingan rakan & $\begin{array}{l}\text { Pendidik dan pemimpin sekolah mendapat maklum balas tentang amalan mereka } \\
\text { setelah diselia oleh rakan. Perbincangan bagi meningkatkan pedagogi } \\
\text { pengajaran dilaksanakan. }\end{array}$ \\
\hline Kumpulan rakan kritikal & $\begin{array}{l}\text { Sekumpulan pendidik yang terdiri daripada lapan hingga } 12 \text { orang bersemuka } \\
\text { secara sukarela untuk menambah baik amalan. }\end{array}$ \\
\hline $\begin{array}{l}\text { Memeta Kurikulum } \\
\text { Kumpulan }\end{array}$ & $\begin{array}{l}\text { Fakulti atau panitia bertemu untuk menyemak pengajaran dan pembelajaran } \\
\text { murid }\end{array}$ \\
\hline $\begin{array}{l}\text { Pusingan Instruksional } \\
\text { Klinikal }\end{array}$ & $\begin{array}{l}\text { Pemerhatian dilakukan secara berpasukan ke atas kelas di dalam atau luar } \\
\text { sekolah bagi mencari amalan terbaik untuk meningkatkan amalan pengajaran. }\end{array}$ \\
\hline Kumpulan Membaca & Kumpulan guru atau panitia membincangkan buku yang dibaca. \\
\hline Pementoran & $\begin{array}{l}\text { Mentor yang berpengalaman dalam pengajaran dan pembelajaran akan } \\
\text { berkongsi pengetahuan dan kemahiran dengan guru novis. }\end{array}$ \\
\hline Kajian pengajaran & $\begin{array}{l}\text { Proses penambahbaikan perancangan pengajaran yang digunakan di seluruh } \\
\text { dunia. Guru berkolaborasi untuk menghasilkan pembelajaran yang berkesan } \\
\text { kepada murid. }\end{array}$ \\
\hline Kajian tindakan & $\begin{array}{l}\text { Boleh dilakukan secara individu atau berkumpulan dengan mengumpul dan } \\
\text { menganalisis data murid bagi menjalankan kajian tindakan. }\end{array}$ \\
\hline Pembelajaran secara kendiri & $\begin{array}{l}\text { Individu melakukan pembelajaran kendiri dengan menghadiri bengkel, kursus, } \\
\text { melakukan kajian tindakan bagi meningkatkan amalan profesionalisme. }\end{array}$ \\
\hline $\begin{array}{l}\text { Rangkaian komuniti } \\
\text { pembelajaran profesional }\end{array}$ & $\begin{array}{l}\text { Komuniti pembelajaran profesional yang menggunakan teknologi tertentu bagi } \\
\text { menghubungkan ahli komuniti yang lain. Antaranya melalui Twitter, Facebook, } \\
\text { Google+. }\end{array}$ \\
\hline Komuniti Pengamal & $\begin{array}{l}\text { Sekumpulan ahli yang mempunyai minat yang sama menambah baik amalan } \\
\text { profesionalisme. Strukturnya boleh dibentuk secara formal atau tidak formal, } \\
\text { sama ada secara bersemuka atau dalam talian, atau kedua-duanya sekali. }\end{array}$ \\
\hline
\end{tabular}

Sumber: Al-Jammal, 2015

Percambahan budaya kolaborasi bergerak bersama dengan hala tuju bagi membangunkan budaya yang menekankan kapasiti dan proses perubahan. Kolaborasi bukan sahaja menekankan kejeleketan antara ahli, malah kepakaran setiap individu turut bercambah supaya setiap ahli dapat memfokuskan kepada arah hala tuju yang sama. Kesepakatan kepakaran dalam kolaborasi merupakan strategi yang diperlukan pemimpin untuk melakukan sesuatu perubahan. Pemimpin secara tidak langsung belajar bagi memastikan organisasi sentiasa bergerak ke hadapan.

Justeru, pelaksanaan kolaborasi profesional yang berjaya memerlukan koordinasi di antara individu, kumpulan dan organisasi (Reeves, Pun \& Chung, 2017). Ketiga-tiga entiti ini perlu 
bagi menyokong segala aktiviti kolaborasi yang dijalankan untuk mencapai sesuatu matlamat atau sasaran yang telah ditetapkan.

\section{Kesimpulan}

Budaya kolaborasi profesional berupaya meningkatkan pembelajaran guru khususnya melalui perkongsian pengalaman, pandangan dan pengajaran dalam komuniti pembelajaran profesional. Hasil daripada perkongsian tersebut, guru dan pentadbir berupaya meningkatkan kepakaran khususnya dalam pengajaran dan pembelajaran murid. Walau bagaimanapun, kolaborasi juga mengurangkan autonomi guru dalam pengajaran dan juga menjejaskan motivasi guru jika kolaborasi tersebut dibentuk atas arahan oleh pihak pentadbir. Kolaborasi sedemikian tidak dapat menjadikan amalan komuniti pembelajaran profesional sebagai budaya kolaborasi yang berterusan dan ini akan turut menjejaskan prestasi sekolah.

Oleh itu, beberapa strategi tertentu diperlukan bagi meningkatkan budaya kolaborasi melalui komuniti pembelajaran profesional. Isu-isu yang membelenggu gerak kerja komuniti pembelajaran profesional perlu ditangani dengan sebaiknya bagi memastikan kelestarian sesebuah kolaborasi. Secara keseluruhannya, budaya kolaborasi profesional mampu dibentuk sekiranya keperluan komuniti pembelajaran profesional disediakan dan diselaraskan mengikut matlamat yang telah ditetapkan.

\section{Rujukan}

Al-Jammal, K. (2015). School as professional learning communities: The case of Lebanese private schools. The International Journal of Humanities \& Social Studies, 3(10), 1-23.

Andin, C., Ambotang, A.S., Kamin, Y., \& Hamzah, R. (2019). Transformasi persekitaran sekolah melalui permuafakatan sekolah dan komuniti luar bandar. Geografia-Malaysian Journal of Society and Space, 15(2), 84-101.

Banerjee, N., Stearns, E., Moller, S., \& Mickelson, R.A. (2017). Teacher job satisfaction and student achievement: The roles of teacher professional community and teacher collaboration in schools. American Journal of Education, 123(2), 1-39.

Bantwini, B.D. (2019). Developing a culture of collaboration and learning among natural science teachers as a continuous professional development approach in a province in South Africa. Teacher Development, 23(2), 213-232.

Blankstein, A.M. (2004). Failure is not an option: Six principles that guide student achievement in high-performing schools. Connecticut: Corwin Press.

Blase, J. (1991) The Politics of Life In Schools: Power, Conflict and Cooperation. London: Sage Publications.

Carpenter, D. (2017). Collaborative inquiry and the shared workspace of professional learning communities. International Journal of Educational Management, 31(7), 1069-1091.

Carpenter, D. (2018). Intellectual and physical shared workspace: Professional learning communities and the collaborative culture. International Journal of Educational Management, 32(1), 121-140.

Cohen, L., Manion, L., \& Morrison, K. (2018). Research methods in education. London: Routledge. 
DuFour, R. (2004). What is a" professional learning community"?. Educational leadership, 61(8), 6-11.

DuFour, R., \& Eaker, R. (1998). Professional learning communities. Bloomington, IN: National Educational Service.

Fullan, M., Quinn, J., \& McEachen, J. (2017). Deep learning: Engage the world change the world. Connecticut: Corwin Press.

Gough, D. (2007). Weight of evidence: A framework for the appraisal of the quality and relevance of evidence. Research Papers in Education, 22(2), 213-228.

Hadfield, M., \& Ainscow, M. (2018). Inside a self-improving school system: Collaboration, competition and transition. Journal of Educational Change, 19(4), 441-462.

Hairon, S., \& Tan, C. (2017). Professional learning communities in Singapore and Shanghai: Implications for teacher collaboration. Compare: A Journal of Comparative and International Education, 47(1), 91-104.

Hargreaves, A. (1994) Changing teachers, changing times: Teachers' work and culture in the postmodern age. London: Cassell.

Hargreaves, A., \& Fullan, M.G. (1992). Understanding teacher development. New York: Teachers College Press.

Hargreaves, A., \& O'Connor, M.T. (2017). Cultures of professional collaboration: Their origins and opponents. Journal of Professional Capital and Community, 2(2), 74-85.

Harris, A., Jones, M., \& Huffman, J.B. (2018). Teachers leading educational reform: The power of professional learning communities. London, UK: Routledge.

Lee, D.H.L., \& Lee, W.O. (2018). Transformational change in instruction with professional learning communities? The influence of teacher cultural disposition in high power distance contexts. Journal of Educational Change, 19(4), 463-488.

Lee, M., \& Louis, K.S. (2019). Mapping a strong school culture and linking it to sustainable school improvement. Teaching and Teacher Education, 81, 84-96.

Leontiev, A.N. (1981). The problem of activity in psychology. In J.V. Wertsch (Ed.), The concept of activity in Soviet psychology (pp. 37-71). Armonk, NY: M.E. Sharpe, Inc.

Little, J.W. (1990). The persistence of privacy: Autonomy and initiative in teachers' professional relations. Teachers college record, 91(4), 509-536.

Little, J. W. (2006). Learning-Centered School Professional Community and Learning-Centered School. Washington, D.C.

Lomos, C., Hofman, R.H., \& Bosker, R.J. (2011). Professional communities and student achievement - a meta-analysis. School Effectiveness and School Improvement, 22(2), 121148.

Lortie, D.C. (1975). Schoolteacher: A sociological study (Vol. 21). Chicago: University of Chicago Press.

Louis, K.S., Marks, H.M., \& Kruse, S. (1996). Teachers' Professional Community in Restructuring Schools. American Educational Research Journal, 33(4), 757-798.

Mohd Faiz Mohd Yaakob, Muhamad Rozaimie Ramle, \& Jamal@Nordin Yunus (2016). Konsep kolaborasi dalam komuniti pembelajaran professional: Satu tinjauan dari perspektif Islam. Geografia-Malaysian Journal of Society and Space, 12(10), 1-9.

Reeves, P.M., Pun, W.H., \& Chung, K.S. (2017). Influence of teacher collaboration on job satisfaction and student achievement. Teaching and Teacher Education, 67, 227-236.

Reichstetter, R. (2006). Defining a professional learning community: A literature review. $E \& R$ Research Alert, 6(5), 1-4. 
Rosenholtz, S.J. (1989). Teachers' workplace: The social organization of schools. White Plains, N.Y. : Addison-Wesley Longman Ltd.

Schaap, H., Louws, M., Meirink, J., Oolbekkink-Marchand, H., Van Der Want, A., Zuiker, I., ... \& Meijer, P. (2018). Tensions experienced by teachers when participating in a professional learning community. Professional Development in Education, 1-18.

Shakenova, L. (2017). The theoretical framework of teacher collaboration. Khazar Journal of Humanities and Social Sciences, 20(2), 34-48.

Siti Nafsiah Ismail, Zuraidah Abdullah, Abdul Jalil Othman, \& Salwati Shafie. (2018). Amalan Komuniti Pembelajaran profesional dalam kalangan guru Bahasa Melayu di Selangor. Jurnal Kepimpinan Pendidikan, 5(4), 1-19.

Sleegers, P., den Brok, P., Verbiest, E., Moolenaar, N.M., \& Daly, A. J. (2013). Toward conceptual clarity: A multidimensional, multilevel model of professional learning communities in Dutch elementary schools. The Elementary School Journal, 114(1), 118137.

Stoll, L., \& Louis, K.S. (Eds.) (2007). Professional learning communities: Divergence, depth and dilemmas. New York, NY: Open University Press/McGraw Hill.

Stoll, L., Bolam, R., McMahon, A., Wallace, M., \& Thomas, S. (2006). Professional learning communities: A review of the literature. Journal of educational change, 7(4), 221-258.

Sun-Keung Pang, N., Wang, T., \& Lai-Mei Leung, Z. (2016). Educational reforms and the practices of professional learning community in Hong Kong primary schools. Asia Pacific Journal of Education, 36(2), 231-247.

Suri, H. (2014). Towards Methodologically Inclusive Research Syntheses. London: Routledge.

Thompson, S.C., Gregg, L., \& Niska, J.M. (2004). Professional learning communities, leadership, and student learning. RMLE Online, 28(1), 1-15.

Trust, T. (2017). Using cultural historical activity theory to examine how teachers seek and share knowledge in a peer-to-peer professional development network. Australasian Journal of Educational Technology, 33(1), 98-113.

Vangrieken, K., Dochy, F., Raes, E., \& Kyndt, E. (2015). Teacher collaboration: A systematic review. Educational research review, 15, 17-40.

Vygotsky, L.S. (1980). Mind in society: The development of higher psychological processes. Cambridge: Harvard university press.

Wan, S.W.Y., Law, E.H.F., \& Chan, K.K. (2018). Teachers' perception of distributed leadership in Hong Kong primary schools. School Leadership \& Management, 38(1), 102-141.

Zhang, J., \& Sun, Y. (2018). Development of a conceptual model for understanding professional learning communities in China: a mixed-method study. Asia Pacific Education Review, 19(4), 445-457.

Zhang, J., Yuan, R., \& Yu, S. (2017). What impedes the development of professional learning communities in China? Perceptions from leaders and frontline teachers in three schools in Shanghai. Educational Management Administration \& Leadership, 45(2), 219-237. 